hardly fail to discover some important fact about the interior structure of a molecule." I think this statement remains as true now as it was thirty-two years ago. There can be no doubt, I think, that spectrum analysis, and especially the magnetisation of the spectral lines, will give us a clue to the inner structure of the atom. I hope that I have stucceeded in imparting to you this, my conviction.

\section{THE ERUPTION OF VESUVIUS IN APRIL, I906.}

THE most complete published account of the eruption of Vesuvius in April last is due to the enlightened liberality of the French Government, which commissioned Prof. Lacroix to study and report upon the eruption, and it is gratifying to find that this, as all other detailed accounts by qualified scientific observers of the eruption of Vesuvius, confirms in every respect the description which we were able to disentangle from contemporary newspaper reports and publish in our issues of April 12 and 19. As a result of Prof. Lacroix's researches he has, in addition to more detailed memoirs published or to come, communicated to the Revue générale des Sciences of October 30 and November 15 an interesting account of the resuit of his observations and deductions, some of which are sufficiently interesting to deserve notice, in extension of what we have already published.

The earlier stage of the eruption was of the Strombolian type, that is to say, the material ejected from the crater was formed by the breaking up of molten lava; it was consequently red hot, and Prof. Mercalli, who was watching the eruption from Torre Annunziata, noticed that the mountain became covered, for from 200 metres to 300 metres from its summit, with a continuous sheet of glowing material, from which blocks incessantly rolled down to lower levels. At oh. $3 \mathrm{rm}$. and again at $2 \mathrm{~h} .4 \mathrm{om}$. a.m. on April 8 violent earthquakes were felt, corresponding to the most violent paroxysms of the eruption, accompanied by a lowering of the height of the cone and a change from the Strombolian to the Vulcanian type of eruption. From this time onward the ejected material was less and less composed of fresh lava, and less and less incandescent, being composed, in increasing degree, of the old solidified lavas and tuffs of the cone.

For several days after April 8 the summit was hidden by a thick cloud of ashes, and when this cleared away the mountain was found to have changed its form, from a pointed to a truncated cone, like that left after the eruption of 1822 , though not so low or with so large a crater. When it became possible to ascend the cone it was found that the new crater was a true caldera, almost circular, of 640 metres to $65^{\circ}$ metres in diameter, surrounded by walls almost vertical except at the top, where a steep talus reached up to the crest, and at the bottom, where a funnelshaped talus sloped down into a cloud of vapour escaping from the fumeroles. The rim was irregular in height and generally sharp-crested, but cut by a deep gap on the north-east, where, for some 80 metres, the crest was not only lower, but comparatively flat-topped; this gap faces the crest of Somma in the direction of Ottajano, where scoriæ and ashes fell in quantity sufficient to crush in the roofs of houses, while the observatory, less than half as far from the crater in the opposite direction, received but a very small quantity of these same ejections. Prof, Lacroix rejects the explanation that this difference was solely due to wind, and considers that he has established a case of oblique eruption, the average direction of projection being, not vertical, but inclined at a considerable angle towards the north-east.

The greater part of the material blown out from the crater fell on the slopes of the cone, which was covered many yards deep with a loose deposit of fine dust, ashes, and blocks of all sizes. Even before the eruption ceased the surface of this deposit began to be broken by dry avalanches, which crashed down on every side, leaving the cone deeply scored by a series of radiating valleys, separated by steep-sided, sharp-crested ridges. Later on, rain-water sinking into and saturating these loose deposits set them in motion as the well-known mud lavas, the mode of flow of which resembles closely that of the molten lava, and still later the rain-water, flowing off the surface, formed torrents of more liquid mud, which cut through the earlier accumulations of the dry avalanches and mud lavas.

The eruption was accompanied by a change in level of the land, but this was confined to the immediate neighbourhood of the volcano, for the tide-gauge shows that there was no alteration in the relative level of land and sea at Naples, while Prof. Mercalli found an elevation of from $30 \mathrm{~cm}$. to $48 \mathrm{~cm}$. between Portici and Vico Equense. Of mineralogical interest is the new mineral, of which the first published description appeared in NATURE of May $3 I$, and the discovery of galena as an addition to the list of Vesuvian minerals.

\section{RUSSIAN OBSERVATIONS OF THE SOLAR ECLIPSE, AUGUST 30, 1905.}

CONSIDERING the unfavourable weather conditions experienced by many of the eclipse parties last year, the members of the Russian expedition, in charge of M. A. Hansky, are to be congratulated on the results they obtained, which have been recently circulated as a publication of the Pulkowa Observatory. The observers were stationed at Alcocebre, on the Mediterranean coast near Valencia. The central line of totality passed almost exactly through the station, and various local conveniences combined to render the choice of site favourable to efficient observation. On August is all the instruments were received in good condition, and after observations had been made for determining the azimuth of the sun's rising point, the various pillars and stands for the apparatus were erected.

Photographs of the corona were taken on two scales:small pictures with the Bredikhine double photographic telescope, furnished with a Zeiss objective of $170 \mathrm{~mm}$. aperture and $800 \mathrm{~mm}$. focal length, giving a field of $12^{\circ} \cdot 4$ in R.A. and $8^{\circ} .8$ in declination; large pictures, for the delineation of fine detail in the coronal streamers, with an objective of 5 inches aperture and $13.28 \mathrm{~m}$. focal length, the light being supplied from a cœlostat $30 \mathrm{~cm}$. in diameter. Spectroscopic observations of the corona and prominences were made with a direct-vision spectroscope without slit, and the polariscopic phenomena examined by the aid of a Savart polariscope. Measurements of the solar radiation were taken with an actinometer and actinograph of Crova's pattern.

Near the time of eclipse the sky became clouded over, but about a minute before totality the sun was seen in clear sky. The corona was seen five or six seconds before totality, and the last ray of sunlight was visible for some two seconds, probably through a deep valley in the moon's limb. This feature is also shown very clearly in the photograph of the chromosphere accompanying the report, which is divided up into a series of bead-like masses at that particular place. Visually the corona was seen of a brilliant, silver-white colour, its brightness increasing rapidly towards the moon's limb. The longest rays seen extended about one and a half lunar diameters, and were situated near the poles of the sun, one at the north and two very fine ones at the south pole. The sky had a green colour similar to that often seen about half an hour before sunrise. Careful examination of the spectrum of the corona during one of the forty-seconds' exposures showed that the continuous spectrum was especially strong in the green, yellow, and red, the latter region being so brilliant that it suggested the possibility of photographing the corona in ordinary daylight by means of suitably prepared colour screens.

With the polariscope the coronal light was seen to be strongly polarised, and the conditions were such that the dark bands were not visible on the sky surrounding the corona. The bands were much stronger when tangential to the sun's limb than when radial. There appeared to be a rotation of about $2 \frac{1}{2}^{\circ}$ of the plane of polarisation, which may possibly be ascribed to the action of a magnetic field round the sun.

Eight photographs of the corona were obtained with the long-focus telescope, the exposures varying from $40-45$ 
seconds, The longest were somewhat over-exposed near the limb, and showed structure to about three-quarters the lunar diameter. Six photographs were taken with the Bredikhine coronagraph, the first of which only was successful, most of the others being much over-exposed. On the good plate the star $\rho$ Leonis was photographed, thereby giving an accurate means of orienting the plates for determining the position angles of the prominences and coronal streamers. These values are tabulated for the more important streamers. M. Hansky considers that the results obtained confirm the idea that the corona varies, not only in form, but in brightness and spectrum, with the sun-spot period. During this last eclipse the brightness was probably ten times that of the full moon, while at epochs of minimum spots the corona has only been about as bright as the full moon. Owing to the sky being frequently clouded over, the actinometric observations are of only small importance, but the character of the record obtained indicates that Crova's instrument is very convenient for such investigations.

Shadow bands were observed before the commencement of totality, the direction of their displacement on the ground being from west to east. They were badly defined at their edges, but became more definite as totality approached. They appeared of a brownish colour, and moved with a velocity of $2-3$ metres per second, the motion being apparently oscillatory, and not translatory. Their distance apart was not more than 25 centimetres. Other observations made at Amposta showed the bands to be $5-7 \mathrm{~cm}$. Wide and $\mathrm{IO}_{-15} \mathrm{~cm}$. apart, the displacement being from northwest to south-east. At the end of totality the corona disappeared immediately, and no shadow bands were seen. The sunlight appeared to return suddenly, without any gradual change such as was observed before totality.

Charles P. Butler.

\section{UNIIERSITY AND EDUCATIONAL INTELLIGENCE.}

OxFord.-The following examiners have been appointed :--In zoology, Dr. J. W. Jenkinson, Exeter College ; in preliminary physics, R. E. Baynes, Christ Church; in preliminary chemistry, H. B. Hartley, Balliol College; in preliminary animal physiology, Prof. F. Gotch, Magdalen College; in preliminary zoology, R. W. T. Günther, Magdalen College; in medicine, Dr. A. E. Garrod, Christ Church; in organic chemistry, N. V. Sidgwick, Lincoln College; in materia medica, Dr. R. Stockman; in anatomy, Prof. A. Thomson, Exeter College; in physiology, Dr. H. M. Vernon, Magdalen College; in pathology, Prof. G. Sims-Woodhead; in forensic medicine, Dr. H. H. Littlejohn; in surgery, D'Arcy Power, Exeter College; in obstetrics, J. S. Fairbairn, Magdalen College.

Dr. J. W. Jenkinson, Exeter College, has been appointed lecturer in comparative and experimental embryology.

$T$. Lindsay, Glasgow University, has been elected to a Brakenbury scholarship in natural science at Balliol College.

An examination for a Radcliffe travelling fellowship of the annual value of 2ool., tenable for three years, will commence on February 26, 1907. Intending candidates should send their names to the regius professor of medicine by February 9 .

Cambridge.-Mr. A. G. Tansley, assistant professor of botany at University College, London, has been appointed lecturer in botany in succession to Mr. A. C. Seward, who has succeeded the late Prof. Marshall Ward in the chair of botany.

The Vice-Chancellor has published a further list of donations to the benefaction fund, which has now reached a sum of $96,400 l$.

Mr. T. G. Bedford, of Sidney Sussex College, has been appointed assistant demonstrator at the Cavendish Iaboratory to hold office from January 1,1907 , to September 30 , igil.

No. 1937 , VOL. 75$]$
Prof. B. Hopkinson has been appointed chairman of the examiners for the mechanical sciences tripos, 1907.

The Arnold Gerstenberg studentship (Ig06) has been awarded to A. E. Baker, Trinity College, for an essay entitled "A Critical Examination of Descartes" Philosophy of Nature."

The special board for biology and geology has adjudged the Walsingham medal for 1906 to W. E. Agur, for his essay on "Researches into the Embryology of the Dipnoi," and W. L. Balls, for his essay entitled "Studies of Egyptian Cotton."

It is proposed that, in accordance with a recommendation of the general board of studies, a university lecturer in hygiene be appointed for a period of five years, in connection with the special board for medicine, and with an annual stipend of $100 l$. payable out of the funds in the hands of the State Medicine Syndicate.

The authorities of Gonville and Caius College, having decided to close their chemical laboratory at the end of the present academic year, a syndicate was appointed on November 8 to consider the assignment of a site tor the extension of the chemical laboratory. The conclusion arrived at is that, of the sites available, the one site which is not liable to considerable objection lies between the chemical laboratory and the new medical schools, with a frontage next Pembroke Street.

The antiquarian committee recommends that it be authorised to hire an old malting house at Neivnham for a period of five years in which to store some of the collec tions under its charge. The need for a new museum of ethnology and archæology is indeed becoming pressing. The University has assigned a site for such a building. and a building fund has been started by Baron von Hügel, curator of the museum, but until that fund is very considerably augmented the University will be compelled to store away many of its treasures in a building inaccessible to students, and quite unworthy of the treasures it contains. The committee also recommends that the numerous small sums which it receives from the financial board for the upkeep of the museum be consolidated, and that an annual grant of $420 l$. be placed at its disposal for each of the five years 1907 to rgir.

THE fourth annual prize distribution of the Sir John Cass Technical Institute was held on December 4, when Sir William Ramsay, K.C.B., F.R.S., delivered an address and distributed the prizes. The chair was taken by Sir Owen Roberts, chairman of Sir John Cass's foundation. In reviewing the work of the institute, Sir William Ramsay dwelt upon the scope and aims of those who follow the study of science with the view of making discoveries, whose main object is to extend the boundaries of science and to gain knowledge, in contrast with those who, on the one hand, restrict their work to duties of a more mechanical character, involving less responsibility, and are satisfied with the discharge of their daily task, and with those, on the other, who find their work and interest in the direction and guidance of business concerns and in the control of their fellow-men. The comparative rewards and the nature of the successes of these various classes of workers were contrasted, and the possibilities of the institute in training students to fill one or more of these different spheres of activity were outlined. Turning to the awards made on the work of the past session, Sir William Ramsay advised students not to aim at prizes; if prizes come, well and good, but they should not be the object of work. The chief aim, he said, should be to get on with the work in hand, to do it as well as possible, even if the labour brings no immediate reward, and to seck for knowledge : for the great thing in life generally is to be, and not to get. Previous to the distribution, Mr. George Baker, chairman of the institute committec, made a short statement of the work of the institute, in which he pointed out that its relation to the industries of East London is beginning to be known and appreciated by manufacturers, and expressed the hope that it would in the course of time prove a real and progressive help to the trades and industries of the distirt. 